\title{
Biossíntese e caracterização de nanocelulose bacteriana para engenharia de tecidos
}

\author{
Biosynthesis and characterization of bacterial \\ nanocellulose for tissue engineering
}

Michele Roberta Fischer ${ }^{1}$, Michele Cristina Formolo Garcia ${ }^{2}$,
André Lourenço Nogueira ${ }^{3}$, Luismar Marques Porto ${ }^{4}$,
Andréa Lima dos Santos Schneider ${ }^{5}$, Ana Paula Testa Pezzin ${ }^{6}$

\begin{abstract}
1,2,3,5 Departamento de Engenharia Química, Universidade da Região de Joinville (UNIVILLE), Rua Paulo Malschitzki 10. Zona Industrial.CEP:89.201-974, Joinville-SC, Brasil. e-mail: michelegarcia@univille.com.br

${ }^{6}$ Mestrado em Engenharia de Processos (MEP), Universidade da Região de Joinville (UNIVILLE).

${ }^{4}$ Departamento de Engenharia Química e Engenharia de Alimentos, Universidade Federal de Santa Catarina (UFSC), Florianópolis, SC, Brasil.
\end{abstract}

\begin{abstract}
RESUMO
Queimaduras causam lesões do revestimento epitelial, a partir de um agente externo, podendo variar desde uma pequena bolha flictena até formas mais graves, capazes de desencadear respostas sistêmicas. O uso de curativos contendo substâncias cicatrizantes e antimicrobianas é uma opção para terapia local. Os curativos de nanocelulose bacteriana (BNC) já demonstraram seu grande potencial de aplicação devido às suas propriedades como alto teor de pureza, alto poder de absorção de água e ótima adaptabilidade biológica. A incorporação de metais na membrana de nanocelulose é bastante promissora. Nanopartículas de prata (NPAgs) têm sido objeto de vários estudos devido às suas propriedades antibacterianas; nitrato de cério, $\mathrm{Ce}\left(\mathrm{NO}_{3}\right)_{3}$, por sua vez, aumenta a eficácia no tratamento por apresentar propriedades imunomoduladoras. O objetivo deste trabalho foi sintetizar e caracterizar membranas de nanocelulose bacteriana funcionalizadas com nitrato de cério e nanopartículas de prata visando aplicação no tratamento de pele humana lesionada por queimadura. O comportamento térmico, interações entre a BNC, $\mathrm{Ce}\left(\mathrm{NO}_{3}\right)_{3}$ e NPAg, bem como a morfologia, capacidade de retenção de água, reidratação e potencial antimicrobiano foram analisadas por termogravimentria (TGA), microscopia eletrônica de varredura (MEV), análise de conteúdo de capacidade de água, capacidade de reidratação e atividade antimicrobiana. A membrana formada pela incorporação de $\mathrm{Ce}\left(\mathrm{NO}_{3}\right)_{3}$ e $\mathrm{NPAgs}$ simultaneamente, e submetida ao tratamento térmico, conservou as propriedades térmicas de ambos os materiais, assim como também boa capacidade de reidratação e um potencial de redução microbiana de 98\% para Staphylococcus aureus. A análise de MEV apresentou alteração na morfologia, redução de poros e a presença de partículas, o que sugere adequada incorporação dos compostos.
\end{abstract}

Palavras-chave: Antimicrobianos, Nanocelulose bacteriana, Gluconacetobacter hansenii, nanotecnologia.

\begin{abstract}
Burns cause lesions of the epithelial lining, from an external agent, and can range from a small injury to more severe forms, capable of triggering systemic responses. The use of dressings containing healing and antimicrobial substances are options for local therapy. Bacterial nanocellulose (BNC) dressings have already demonstrated their great potential due to their properties such as high purity, high water absorption capacity and optimum biological adaptability. The incorporation of metals in the nanocellulose membrane is quite promising. Silver nanoparticles (AgNPs) have been studied because of their antibacterial properties; cerium nitrate, $\mathrm{Ce}\left(\mathrm{NO}_{3}\right)_{3}$, on the other hand, increases the efficacy of the treatment because of its immunomodulatory properties. The objective of this work was to synthesize and characterize bacterial nanocellulose membranes functionalized with cerium nitrate and silver nanoparticles aiming the treatment of human skin that has been subject to burning injuries. Thermal behavior, interactions between BNC, $\mathrm{Ce}\left(\mathrm{NO}_{3}\right)_{3}$ and AgNP, as well as morphology, water retention capacity, rehydration capacity and antimicrobial potential were analyzed by thermogravimetry (TGA), scanning electron microscopy (SEM), analysis of water content, rehydration capacity and antimicrobial activity. Membranes formed by incorporation of $\mathrm{Ce}\left(\mathrm{NO}_{3}\right)_{3}$ and AgNPs simultane-
\end{abstract}


ously, and submitted to heat treatment, preserved thermal properties of both materials, as well as a good rehydration capacity and a microbial reduction potential of $98 \%$ for Staphylococcus aureus. SEM analysis showed changes in morphology, pore size reduction and the presence of particles, what suggest successful incorporation of the compounds.

Keywords: Antimicrobials, Bacterial nanocellulose, Gluconacetobacter hansenii, Nanotechnology.

\section{INTRODUÇÃO}

As lesões por queimadura são uma importante causa de morbidade, incluindo hospitalização prolongada, desfiguração e incapacitação do paciente. As queimaduras de pele são causadas principalmente por calor, bem como por exposição à radioatividade, radiação, eletricidade, produtos químicos e fricção. A Organização Mundial da Saúde estima que os ferimentos por queimaduras causem anualmente 265.000 mortes no mundo [1]. Fatores como o rompimento da barreira da pele, pronta disponibilidade de nutrientes bacterianos, destruição do suprimento vascular para a pele queimada e perturbações sistêmicas, quando combinados podem levar à imunossupressão, tornando as queimaduras susceptíveis à infecção [2].

Os curativos de nanocelulose bacteriana (BNC) já demonstraram potencial no processo de cicatrização, sendo comercializados sobre os nomes de Membracel ${ }^{\circledR}$, Bionext ${ }^{\circledR}$, entre outros. Suas principais propriedades são: controle da dor e inflamação, manutenção de umidade na ferida, assim como dos fatores de crescimento e defesa, favorecendo a granulação e crescimento dérmico, menor taxa de contaminação externa, visualização direta do aspecto e quantidade de secreção, diminuição ou ausência nas trocas de curativos, diminuindo lesões epidérmicas com comodidade e segurança ao paciente [3].

A celulose é um dos polímeros biodegradáveis mais disponíveis na natureza, podendo ser também sintetizada, por exemplo, por algumas bactérias do gênero Gluconacetobacter [4], sendo secretada extracelularmente sob a forma de uma rede de nanofibras, randomicamente distribuídas, que estão interligadas e formam uma estrutura tridimensional altamente reticulada com uma matriz única e porosa. Muitos estudos descrevem uma vasta gama de aplicações para a BNC, podendo ser utilizada na indústria alimentar, telecomunicações, como dispositivo eletroacústico, tal como diafragmas de telefone [5], entre diversas outras aplicações.

A BNC possui propriedades únicas, essenciais para a engenharia de tecidos, incluindo alta capacidade de absorção de água, elevada cristalinidade e boas propriedades mecânicas, quando comparada a outros biopolímeros, tais como colágeno, quitina e gelatina. Na área médica já foram relatados estudos para aplicação como vasos sanguíneos artificiais para microcirurgia, arcabouços para engenharia tecidual, substituto de pele e como sistema carreador de fármacos (drug delivery), além de funcionar como barreira contra micro-organismos em feridas e queimaduras, o que auxilia no processo de cura e também ameniza a dor e reduz o tempo de cicatrização [6]. Permeável a gases e impermeável a líquidos, a pele artificial, como também é conhecida a membrana de nanocelulose, forma uma barreira bacteriológica, deixando o ferimento respirar. Outra vantagem é a possibilidade de atenuação ou mesmo a eliminação da dor nesses pacientes. Utilizada como curativo, reduz o tempo de tratamento e, com isso, diminui também o custo das internações de pacientes com queimaduras e feridas crônicas [7].

Estudos recentes têm relatado a incorporação de substâncias ativas em sua estrutura permitindo a modulação de propriedades específicas [4]. Em paralelo, a estrutura da BNC também tem sido utilizada como molde para a incorporação de metais com dimensões nanométricas. A incorporação de metais na membrana de nanocelulose é interessante devido às propriedades antibacterianas apresentadas por alguns metais [8].

No século 20, a introdução de antibióticos e antifúngicos e o uso de antimicrobianos tópicos que eram extensivamente aplicados em queimaduras e a adoção generalizada de excisão precoce e enxertia, melhoraram a expectativa de sobrevivência. Entretanto, o aumento da resistência microbiana aos antibióticos e outros agentes antimicrobianos tem levado a uma busca renovada por abordagens alternativas de prevenção e combate às infecções. Nos últimos anos têm sido investigadas várias dessas alternativas: preparações de prata (nanocristalina e de liberação lenta), peptídeos antimicrobianos, terapia fotodinâmica tópica, preparações de quitosana, novas formulações de liberação de iodo, terapia com fagos e produtos naturais como mel e óleos essenciais [2].

As nanopartículas metálicas são uma alternativa eficaz no combate às bactérias patogênicas. Dentre as nanopartículas com função bactericida podemos citar as nanopartículas de prata (NPAg), de óxido de cobre (NPCuO), de dióxido de titânio $\left(\mathrm{NPTiO}_{2}\right)$, de óxido de ferro $\left(\mathrm{NPFe}_{2} \mathrm{O}_{3}\right)$ e nanopartículas de óxido de zinco (NPZnO) [9].

A prata é mais conhecida por suas propriedades antimicrobianas potentes. Já no século XVIII existiam registros de aplicação da prata para tratamento de feridas. Sob a forma de nitrato de prata, foi utilizada para o tratamento de úlceras, e íons de prata foram identificados como antimicrobianos ainda no século XIX. A prata coloidal foi aprovada para tratamento de feridas pela FDA em 1920. Em 1968, nitrato de prata foi combinado com um antibiótico sulfonamida para produzir sulfadiazina de prata, um agente antibacteriano tópico prescrito para o cuidado de 
queimaduras, e que ainda está em uso. Curativos contendo prata são frequentemente utilizados em substituição aos antibióticos, devido ao surgimento e aumento de bactérias resistentes aos antibióticos. Nanopartículas de prata também estão sendo avaliadas como agentes antivirais e para a liberação controlada de fármacos [10].

O cério é um metal da família dos lantanídeos, que tem propriedades bacteriostáticas, e apresenta maior eficácia sob a forma de nitrato de cério contra uma ampla gama de bactérias. Uma formulação de sulfadiazina de prata e nitrato de $\mathrm{Ce}^{3+}$ (conhecida como Flammacerium ${ }^{\circledR}$ ) já foi usada no tratamento de feridas por queimadura [10]. Acredita-se que o nitrato de cério exerce um efeito protetor contra a imunossupressão pós-queimadura causada por um complexo de lipoproteínas de elevado peso molecular (3 MDa).

Nesse contexto, este trabalho propõe o uso de membranas de celulose bacteriana funcionalizadas com nanopartículas de prata e nitrato de cério buscando proporcionar a regeneração tecidual pós-queimadura, reduzindo o índice de infecções.

\section{MATERIAIS E MÉTODOS}

\subsection{Micro-organismo e condições de cultivo}

A bactéria utilizada nesse estudo foi a Gluconacetobacter hansenii ATCC 23769, armazenada em temperatura de $-80^{\circ} \mathrm{C}$, tendo o glicerol como agente crioprotetor.

O meio de cultivo utilizado tanto na da fase de ativação das células (pré-inóculo) quanto na fase de produção das membranas foi o mesmo, constituído de manitol $\left(20 \mathrm{~g} \cdot \mathrm{L}^{-1}\right)$, peptona de soja $\left(5 \mathrm{~g} \cdot \mathrm{L}^{-1}\right)$, extrato de levedura $\left(5 \mathrm{~g} \cdot \mathrm{L}^{-1}\right)$, fosfato dissódico $\left(2,7 \mathrm{~g} \cdot \mathrm{L}^{-1}\right)$ e ácido cítrico $\left(1,15 \mathrm{~g} \cdot \mathrm{L}^{-1}\right)$, sendo autoclavado a $121^{\circ} \mathrm{C}$ por 20 $\min [11]$.

O cultivo foi conduzido em frascos Erlenmeyer. As células foram ativadas em frasco Erlenmeyer de $500 \mathrm{~mL}$ contendo $100 \mathrm{~mL}$, incubadas a temperatura ambiente sob condições estáticas por 2 dias. Após este período, o pré-inóculo foi transferido para o meio de cultivo $(20 \%$ v/v). Esta etapa foi conduzida em frascos Erlenmeyer de $250 \mathrm{~mL}$ com $50 \mathrm{~mL}$ de meio de cultivo incubados em estufa a $30^{\circ} \mathrm{C}$ e condição estática durante 12 dias para a formação das mantas hidratadas de BNC [12].

\subsection{Purificação}

A membrana formada na superfície do caldo de cultivo foi lavada com água destilada para remover o caldo de cultivo remanescente e, em seguida, foi tratada com solução $0,1 \mathrm{~mol} \cdot \mathrm{L}^{-1}$ de $\mathrm{NaOH}$, em banho-maria a $80^{\circ} \mathrm{C}$, durante 60 minutos, para remover impurezas bacterianas e demais contaminantes. Após este tratamento foi lavada com água destilada até atingir $\mathrm{pH}$ 7,0, armazenada em água destilada e autoclavada para evitar contaminação [13].

\subsection{Síntese e incorporação das NPAgs e do $\mathrm{Ce}\left(\mathrm{NO}_{3}\right)_{3}$ à membrana}

A síntese das NPAgs foi realizada pelo método de redução química, utilizando nitrato de prata, $\mathrm{AgNO}_{3}$, de pureza > 99\% (Cennabras) como sal precursor, e boroidreto de sódio, $\mathrm{NaBH}_{4}$, P.A. (Cinética) como agente redutor. Um aminosilano, o aminoetil-aminopropil-trimetoxisilano, AES (Xiameter OFS 6020, 70-90\% de pureza, Dow Corning), foi empregado como agente estabilizante na síntese das nanopartículas de prata, e agente de acoplamento destas nanoestruturas na superfície das membranas de BNC. Inicialmente, o Ag$\mathrm{NO}_{3}(0,0157 \mathrm{~g})$ e $\mathrm{o}$ agente estabilizante $\left(10,8 \mathrm{mmol} \cdot \mathrm{L}^{-1}\right.$ de AES) foram adicionados em água deionizada $(90 \mathrm{~mL})$ e mantidos sob agitação durante 48 horas $\left(600 \mathrm{rpm}, 20^{\circ} \mathrm{C}\right)$ [14]. As sínteses foram conduzidas sob agitação constante $(600 \mathrm{rpm})$ e temperatura de $20^{\circ} \mathrm{C}$ em um reator de $100 \mathrm{~mL}$ de vidro boro-silicato encamisado, conectado a um banho termocriostático para controlar a temperatura do meio reacional. A solução de $\mathrm{NaBH}_{4}\left(10 \mathrm{~mL}\right.$ com concentração de $\left.0,46 \mathrm{mmol} \cdot \mathrm{L}^{-1}\right)$, preparada no momento da síntese e mantida em banho de gelo, foi adicionada à solução de nitrato de prata e estabilizante (AES) a uma vazão de aproximadamente $1,0 \mathrm{~mL} \cdot \mathrm{min}^{-1}$ por meio de uma bureta graduada de vidro. Após o término da dosagem da solução do agente redutor, o sistema foi mantido sob agitação por 30 minutos para garantir o término da reação.

$\mathrm{O} \mathrm{Ce}\left(\mathrm{NO}_{3}\right)_{3}$ foi adquirido do fabricante Neon sob forma de $\mathrm{Ce}\left(\mathrm{NO}_{3}\right) \cdot 6 \mathrm{H}_{2} \mathrm{O}, 99 \%$ P.A.

Para viabilizar a absorção das NPAgs e $\mathrm{Ce}\left(\mathrm{NO}_{3}\right)_{3}$ na superfície das membranas de BNC, as mesmas foram submetidas a um processo mecânico de remoção do excesso de água para favorecer o intumescimento com as soluções preparadas: $5 \mathrm{~mL}$ de solução de $2,2 \%$ de $\mathrm{Ce}\left(\mathrm{NO}_{3}\right) \cdot 6 \mathrm{H}_{2} \mathrm{O}, 5 \mathrm{~mL}$ de solução com 100 ppm de NPAg e $5 \mathrm{~mL}$ de solução $100 \mathrm{ppm}$ de NPAg, 2,2\% m/m de Ce( $\left(\mathrm{NO}_{3}\right) \cdot 6 \mathrm{H}_{2} \mathrm{O}$. Aguardou-se $48 \mathrm{~h}$ para que ocorresse a absorção da solução às membranas. No período de absorção, as membranas foram mantidas em temperatura ambiente. 
As amostras foram divididas em dois grupos, A e B, de acordo com a Figura 1. As amostras do grupo B foram submetidas a um tratamento térmico $\left(121^{\circ} \mathrm{C}\right.$ por $2 \mathrm{~h}$ em autoclave da Marca PHLIPS, modelo PI3103), com o objetivo de incorporar quimicamente as NPAgs na superfície da BNC por meio do AES como um agente de acoplamento e, desta forma, obter um material funcionalizado. Os grupos funcionais metoxisilano (-Si-O- $\mathrm{CH}_{3}$ ) presentes na molécula do AES se hidrolisam quando em contato com a água, formando grupos silanol (-Si-OH). Na presença de superfícies ricas em hidroxilas $(\mathrm{OH})$, como é o caso da BNC, estes grupos funcionais formam ligações siloxanas por meio de reações de condensação [15]. Como a prata se liga aos nitrogênios presentes nos grupos funcionais amina $\left(\mathrm{NH}_{2}\right.$ e $\left.\mathrm{NH}\right)$ do AES por meio de ligações de coordenação [16], as nanopartículas deste metal nobre acabam sendo incorporadas quimicamente na superfície das membranas de BNC, funcionalizando-as.

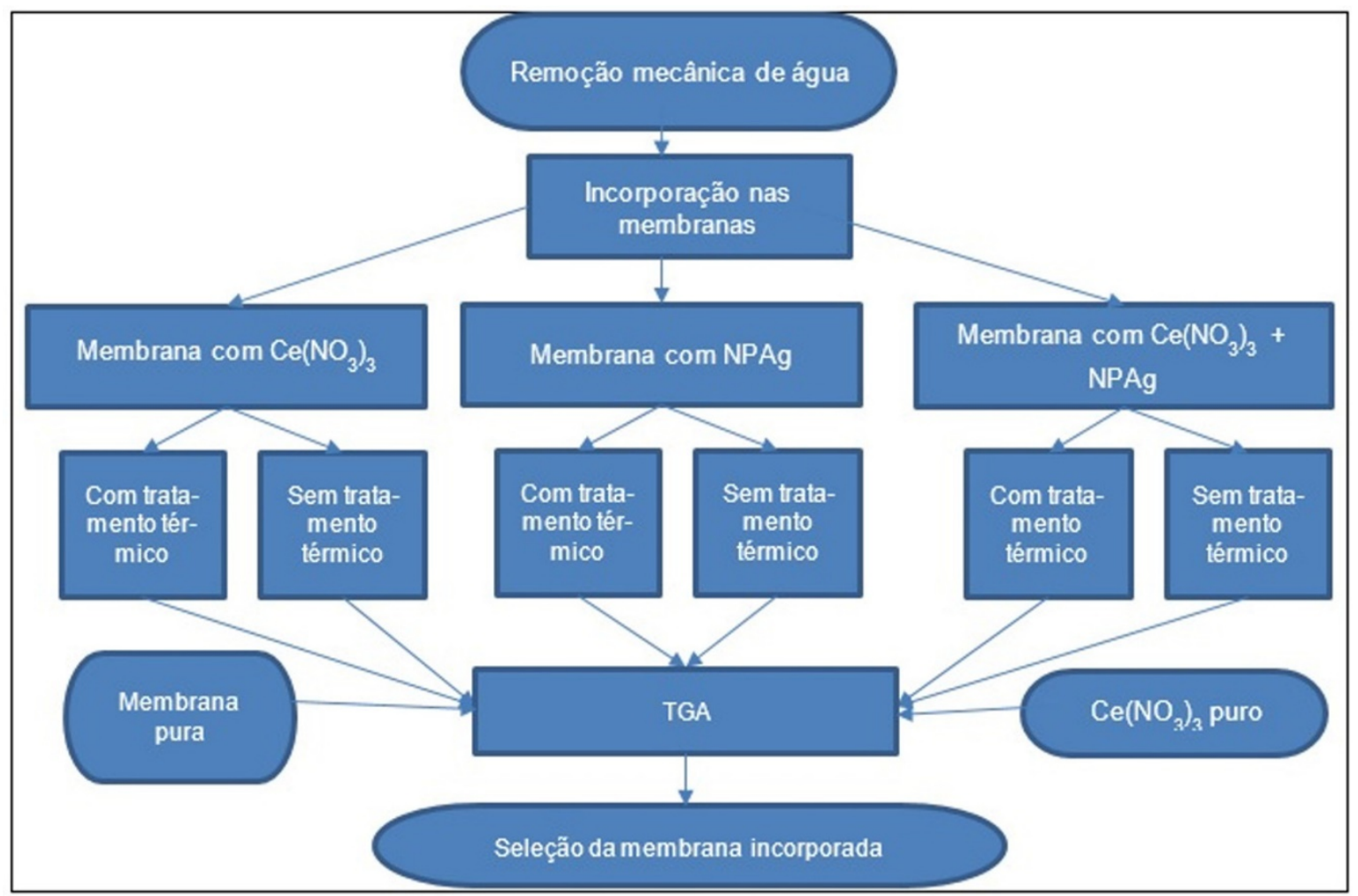

Figura 1: Fluxograma para seleção da membrana incorporada.

\subsection{Caracterização das Nanopartículas de Prata}

As nanopartículas de prata foram caracterizadas por espectrofotometria de UV-Vis (Shimadzu UV 1601PC) para se avaliar as propriedades ópticas de absorbância da luz. Para isso, as amostras foram diluídas em água deionizada na razão de 1:7 (v/v) e, em seguida, submetidas a leituras de absorção em uma cubeta de vidro com caminho óptico de $10 \mathrm{~mm}$.

Com o propósito de avaliar a geometria e estimar o tamanho médio e a dispersão de tamanhos das nanopartículas, análises de microscopia eletrônica de transmissão (MET) foram conduzidas em um microscópio JEOL JEM-2100 operando com tensão de 200 kV. Para esta análise, 10 gotas da dispersão coloidal concentrada foram adicionadas em grids de cobre de 300 mesh recobertos com filme de carbono. As imagens de MET foram realizadas com uma magnificação de 300.000 vezes.

\subsection{Liofilização da membrana de BNC}

As membranas de BNC pura e as membranas de BNC incorporadas foram previamente congeladas e desidratadas pelo processo de liofilização utilizando Liofilizador Terroni LT 1000 por 24 h e armazenadas em dessecador. 


\subsection{Caracterização da BNC}

\subsubsection{Análise Termogravimétrica (TGA)}

A análise termogravimétrica foi realizada sob atmosfera oxidante, com razão de aquecimento de $10^{\circ} \mathrm{C} \cdot \mathrm{min}^{-1}$, entre 25 e $1000^{\circ} \mathrm{C}$ no equipamento TA Instruments TGA Q50. Os parâmetros experimentais foram ajustados pelo software do equipamento, versão TA2000. Esta análise foi usada como critério para selecionar o método de incorporação da solução de $\mathrm{Ce}\left(\mathrm{NO}_{3}\right)_{3}$ e NPAg descrito no item 2.3.

\subsubsection{Microscopia eletrônica de varredura (MEV)}

Para esta análise as amostras de BNC pura e BNC incorporada foram recobertas com carbono. O equipamento utilizado foi microscópio eletrônico de varredura JEOL, modelo JSM-6701F.

\subsubsection{Determinação do conteúdo de água}

Para a determinação do conteúdo de água na BNC pura e BNC incorporada, removeu-se o excesso de água da BNC, e determinou-se a massa da membrana hidratada (mh); após, as amostras foram liofilizadas conforme o item 2.6 e foi determinada sua massa seca (ms) [17]. A análise foi realizada em triplicada.

O resultado do conteúdo de água na BNC foi calculado de acordo com a equação 1:

$$
\text { Conteúdo de água }=\frac{\mathrm{mh}-\mathrm{ms}}{\mathrm{mh}} \times 100
$$

\subsubsection{Determinação da capacidade de reidratação}

As membranas liofilizadas de BNC pura e BNC incorporada foram imersas em $200 \mathrm{~mL}$ de água deionizada e mantidas à temperatura ambiente. A massa da BNC reidratada (mr) foi determinada após 2, 24, 48, 72 e 96 horas. Os ensaios foram realizados em triplicada com corpos de prova com diâmetro de 70 mm.

A capacidade de absorção de água foi obtida através da equação 2 [17]:

$$
\text { Capacidade de reidratação }=\frac{\mathrm{mr}-\mathrm{ms}}{\mathrm{mr}} \times 100
$$

\subsubsection{Atividade antimicrobiana}

O procedimento adotado para avaliar a atividade antimicrobiana das amostras de BNC pura e incorporada seguiu o padrão estabelecido na norma ASTM E2180-07, de 2012 [18]. Amostras foram cortadas nas medidas de 3 por $3 \mathrm{~cm}$ e depositadas no fundo de placas de Petri estéreis, sendo este ensaio realizado em triplicada para cada amostra e para cada micro-organismo. A atividade antimicrobiana foi avaliada sobre os microorganismos Staphylococcus aureus (Gram-positivo) e Pseudomonas aeruginosa (Gram-negativo). Testou-se ainda os meios de cultivo Ágar Tripsina de Soja (TSA), recomendado pela norma e o meio Brain Heart Infusion (BHI).

\section{RESULTADOS E DISCUSSÃO}

\subsection{Biossíntese da membrana de BNC}

As membranas de BNC sintetizadas pela bactéria Gluconacetobacter hansenii ATCC 23769, incubada em meio estático a $30^{\circ} \mathrm{C}$ por um período de 12 dias, formaram-se na superfície do cultivo líquido. Após a purificação, as membranas apresentaram um aspecto gelatinoso, sob a forma de um hidrogel claro, translúcido, conforme observado na Figura 2. 


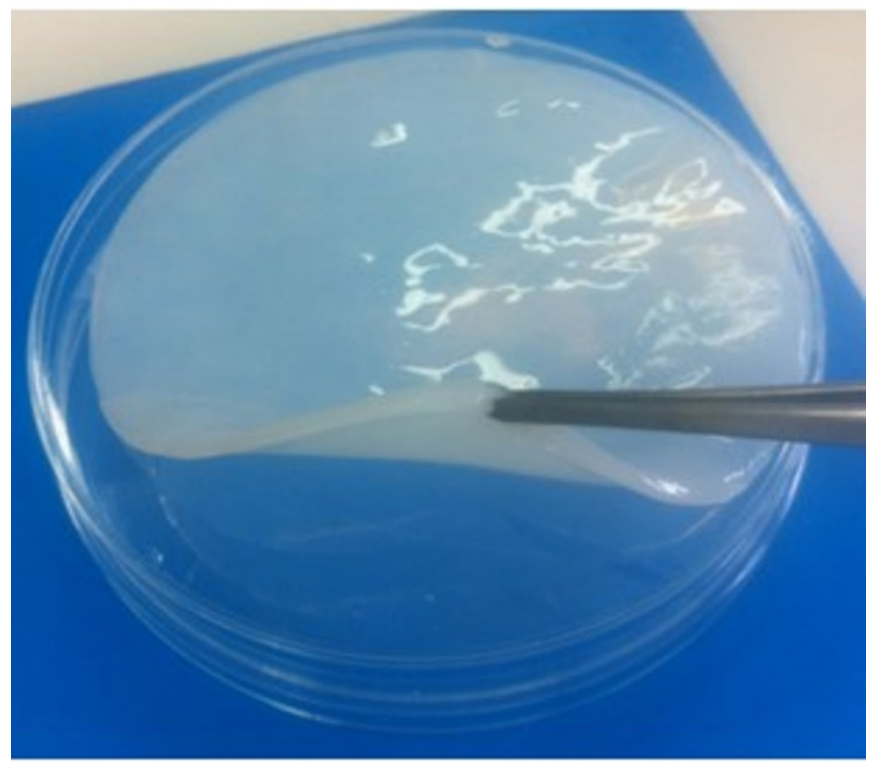

Figura 2: Membrana de BNC obtida após a etapa de purificação.

\subsection{Caracterização das NPAg}

As nanopartículas de prata (NPAgs) foram caracterizadas por espectrofotometria de UV-Vis e microscopia eletrônica de transmissão (MET), conforme metodologias descritas na seção 2. Na Figura 3 é mostrada uma imagem de MET das NPAgs sintetizadas e incorporadas nas membranas de BNC. Como observado, as nanopartículas apresentaram forma geométrica preferencialmente esférica e tamanhos variando entre 5 e $10 \mathrm{~nm}$, aproximadamente. Estes resultados demonstraram que o aminosilano usado agiu eficientemente como uma barreira, impedindo a agregação entre os nanocristais formados e controlando o crescimento das nanopartículas [19].

De acordo com o espectro de UV-Vis apresentado na Figura 4 as NPAgs sintetizadas apresentaram uma absorbância máxima em torno de 411 nm. A máxima absorção de luz em comprimentos de onda próximos a este valor são um indicativo da formação de nanopartículas de prata com geometria tendendo à esférica, como verificado nos resultados de MET, pois as propriedades ópticas de nanoestruturas são fortemente dependentes das características morfológicas das mesmas [16]. Resulatdos semelhantes foram reportados por Nogueira et al. (2014 e 2016) [14-15].

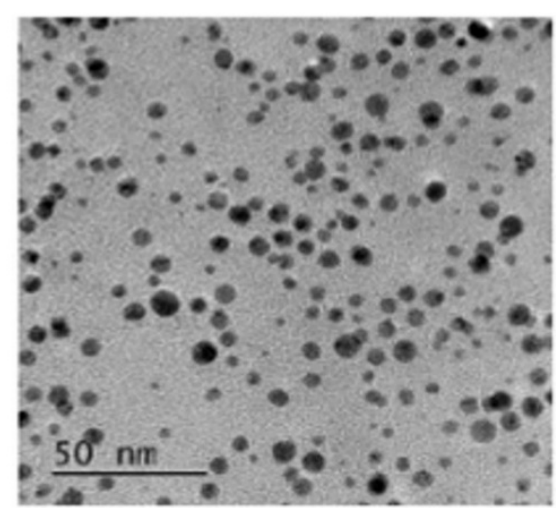

Figura 3: Imagem de MET das NPAgs.

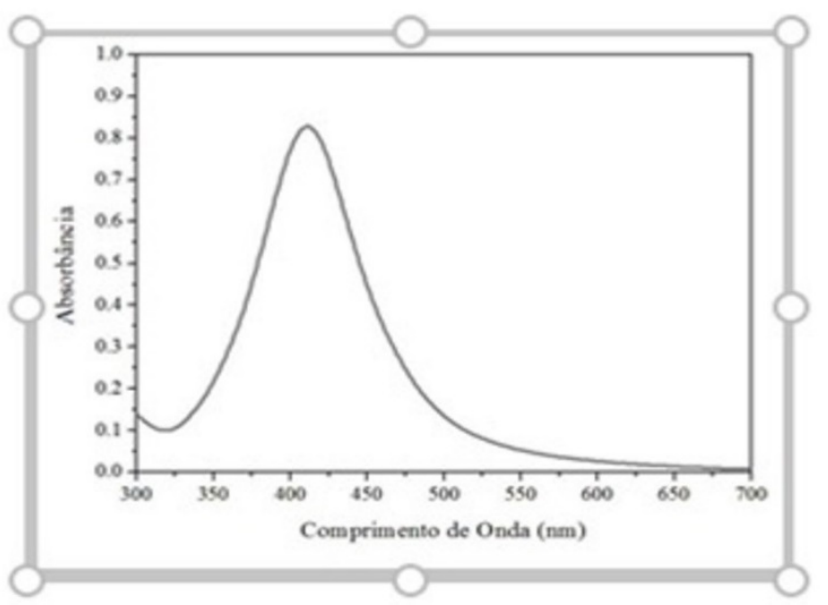

Figura 4: Espectro de absorbância das NPAgs. 


\subsection{Adição de nitrato de cério e nanopartícula de prata à membrana}

Após $48 \mathrm{~h}$ de imersão, as membranas de BNC absorveram $5 \mathrm{~mL}$ das três composições de solução de $\mathrm{Ce}\left(\mathrm{NO}_{3}\right)_{3}$ e NPAgs testadas, alterando a cor de branco translúcido para amarelo translúcido (Figura 5).

A mudança na coloração da BNC incorporada com $\mathrm{Ce}\left(\mathrm{NO}_{3}\right)_{3}$ e NPAg sugere transferência destas partículas para as membranas de BNC.

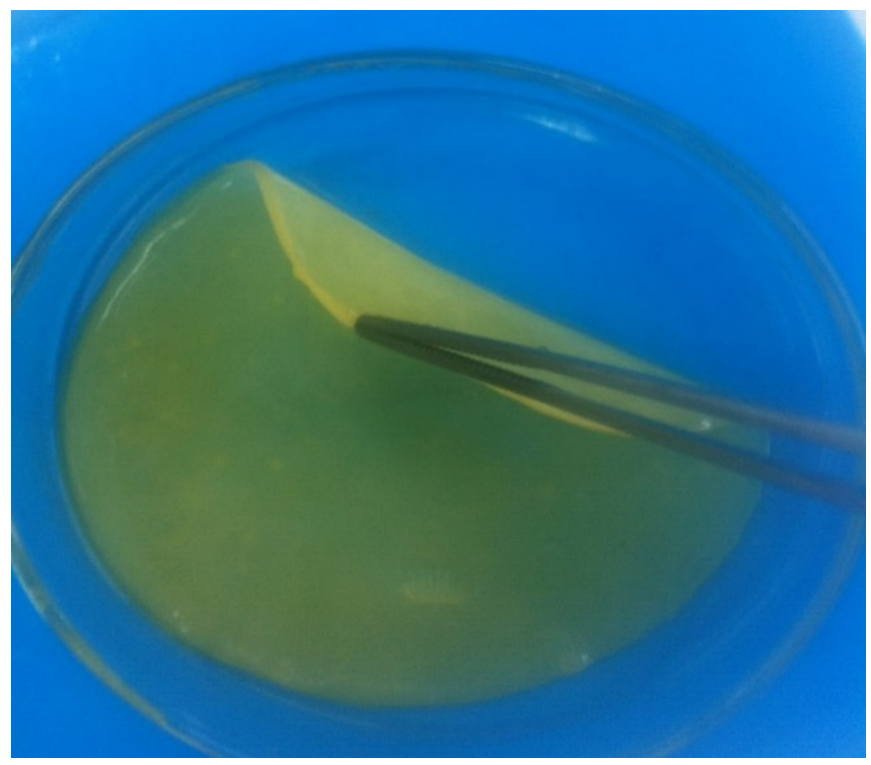

Figura 5: Membrana de BNC incorporada com $\mathrm{Ce}\left(\mathrm{NO}_{3}\right)_{3}$ e NPAg.

Onofre (2014) [20] também observou, em seus estudos com filmes poliméricos de ágar, agarose e keffirina incorporados com nanopartículas de prata, já durante a síntese das NPAg, que este processo era evidenciado pela mudança na coloração da solução, de incolor para amarelado, indicando a redução dos íons $\mathrm{Ag}^{+}$para $\mathrm{Ag}^{0}$, fato também observado por Alcântara (2013) [21].

\subsection{Análise termogravimétrica (TGA)}

Com o intuito de conhecer o comportamento térmico do $\mathrm{Ce}\left(\mathrm{NO}_{3}\right)_{3}$ e $\mathrm{BNC}$, amostras destes foram submetidas à análise TGA isoladamente. Para efeito de comparação, as figuras 6 e 7 mostram o comportamento do $\mathrm{Ce}\left(\mathrm{NO}_{3}\right)_{3}$ e BNC. As propriedades térmicas dos materiais, determinadas a partir destas curvas, encontram-se reunidas na Tabela 1.

Observou-se que o perfil de decomposição do $\mathrm{Ce}\left(\mathrm{NO}_{3}\right)_{3}$ (Figura 6) ocorreu em três etapas, sendo a primeira até $100^{\circ} \mathrm{C}$, devido à eliminação de água. O nitrato de cério é um sal higroscópico, o que pode ser constatado pela análise, na qual se observa uma perda de massa de $6 \%$ até esta temperatura, mesmo a amostra tendo sido seca anteriormente à análise. A segunda e terceira etapas de perda de massa ocorreram em Tonset $_{2} 199^{\circ} \mathrm{C}$ e Tonset ${ }_{3} 252^{\circ} \mathrm{C}$ (Tabela 1). De acordo com Queiroz et al. (2001) [22], estas etapas estão relacionadas com a eliminação dos nitratos e nitritos. A análise foi conduzida até $1000^{\circ} \mathrm{C}$, observando-se ao final do processo um resíduo de $40 \%$ que pode ser atribuído ao metal cério que não sofre degradação até esta temperatura. 


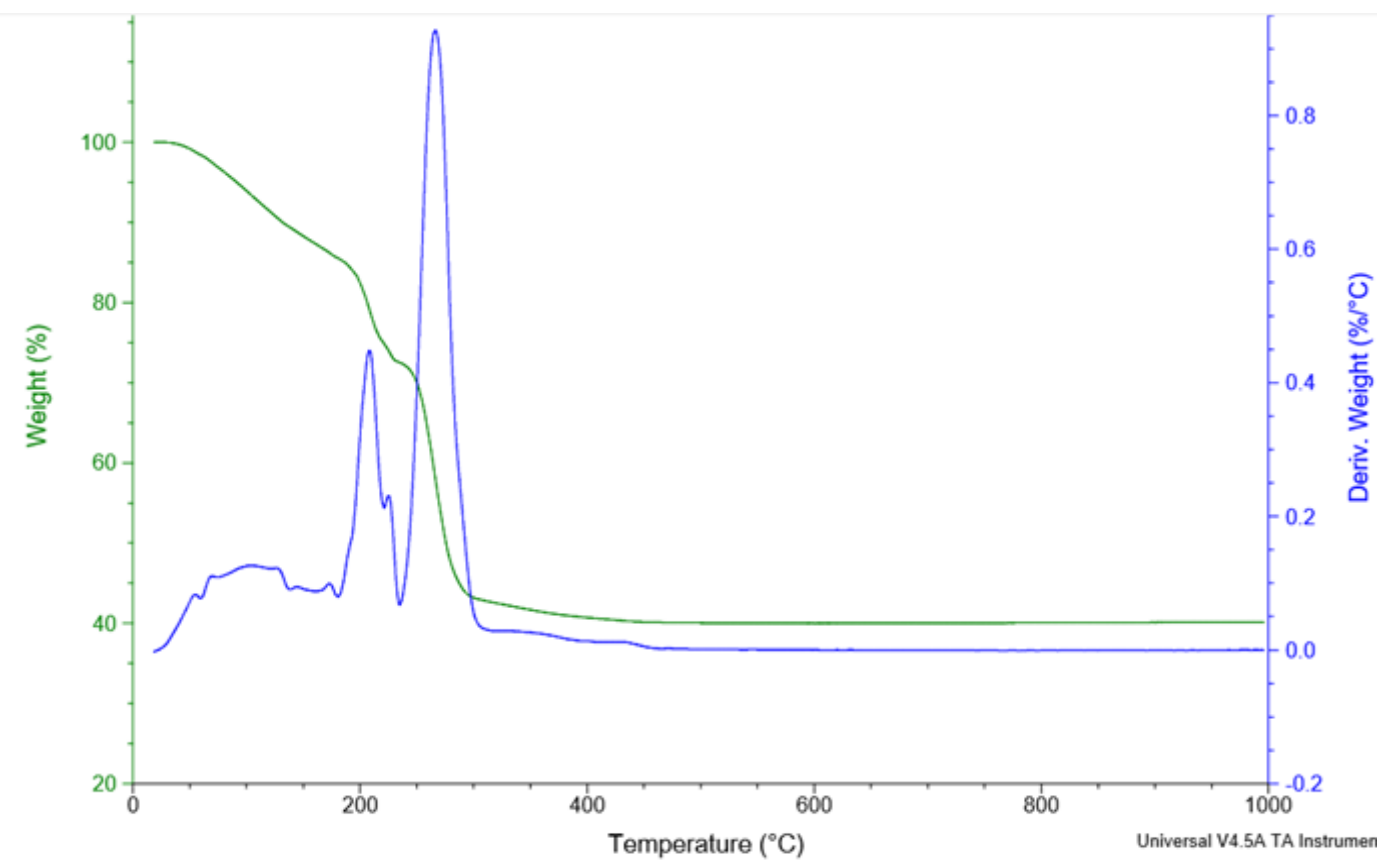

Figura 6: Curvas termogravimétricas (TG e DTG) do Ce( $\left(\mathrm{NO}_{3}\right)_{3}$.

As NPAg não foram analisadas isoladamente por esta técnica devido à sua manutenção em solução aquosa.

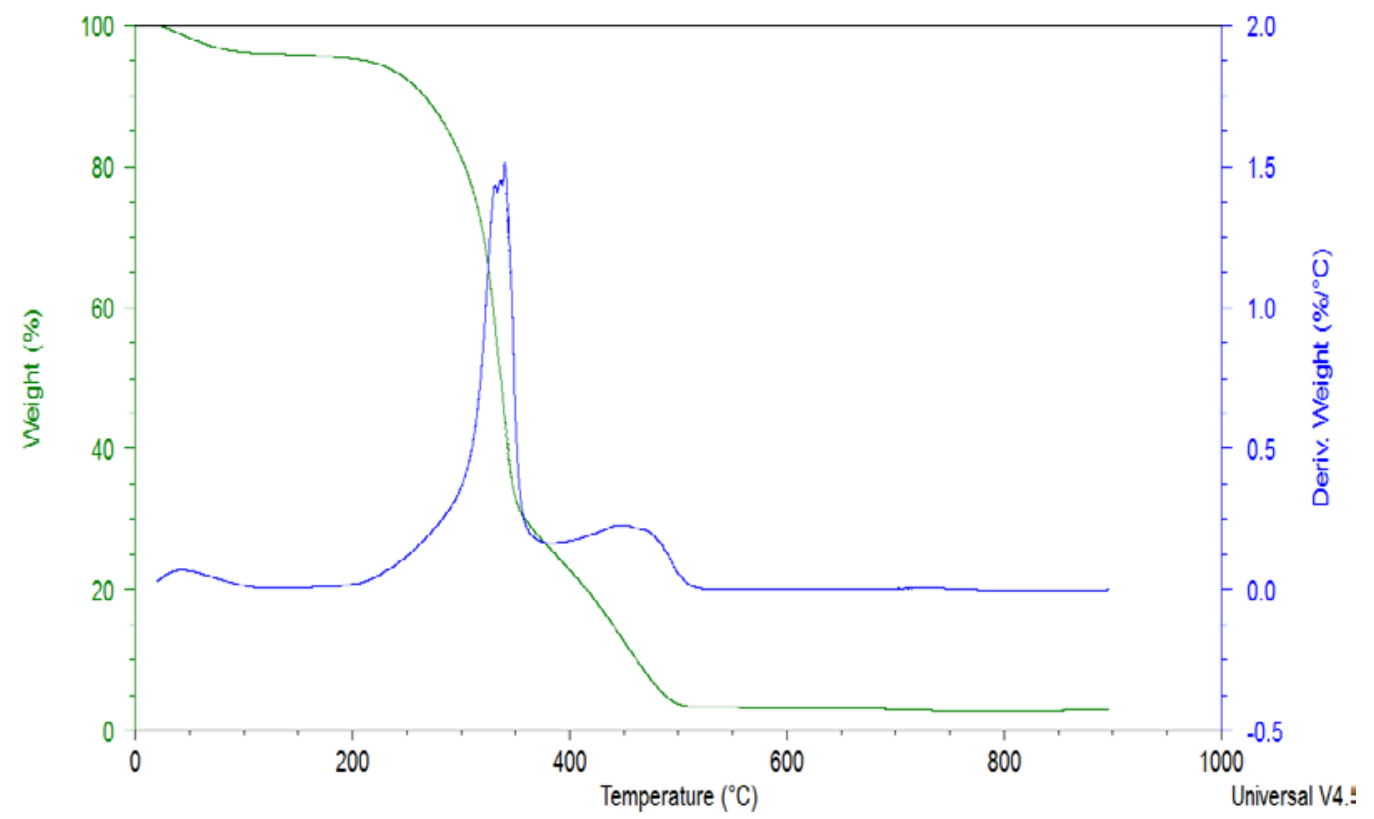

Figura 7: Curvas termogravimétricas (TG e DTG) da membrana de BNC pura.

É possível observar que o perfil de perda de massa para a BNC pura (Figura 7) ocorre em três eventos. $\mathrm{O}$ primeiro evento térmico ocorreu até $100^{\circ} \mathrm{C}$ e representou uma perda de massa de $3,8 \%$ associada à perda de água da amostra. O segundo evento é atribuído à degradação da celulose, que inclui despolimerização, decomposição das unidades de glicose e desidratação. A temperatura de início de degradação térmica $\left(\mathrm{T}_{\text {onset } 4}\right)$ foi de $308^{\circ} \mathrm{C}$ e a temperatura na qual a degradação é máxima $\left(\mathrm{T}_{\max 4}\right)$ foi de $340^{\circ} \mathrm{C}$, com perda de massa de 
68\% (Tabela 1). Resultados semelhantes também foram encontrados por Lima et al. (2015) [23] e Silveira (2016) [13]. O terceiro evento foi atribuído por Teixeira et al. (2010) [24] à degradação de resíduos carbonáceos; este ocorre entre 350 e $500^{\circ} \mathrm{C}$, com perda de massa de $24 \%$. Após esta temperatura não foi observado mais nenhum evento térmico, restando um resíduo não degradado de $3 \%$.

\subsubsection{Análise do comportamento térmico da BNC incorporada com $\mathrm{Ce}\left(\mathrm{NO}_{3}\right)_{3} \mathrm{com}$ e sem tratamento térmico}

A Figura 8 apresenta as curvas de TG e DTG para as amostras de BNC incorporadas com Ce( $\left(\mathrm{NO}_{3}\right)_{3} \mathrm{Com}$ e sem tratamento térmico. Nas amostras de BNC incorporadas observou-se uma redução em $\mathrm{T}_{\text {onset2 }}$ de $199^{\circ} \mathrm{C}$ referente ao segundo estágio de degradação térmica do $\mathrm{Ce}\left(\mathrm{NO}_{3}\right)_{3}$ puro para $148^{\circ} \mathrm{C}$ na amostra de $\mathrm{BNC}$ incorporada e sem o tratamento térmico. No entanto, após o tratamento térmico, esse mesmo estágio de decomposição térmica praticamente não sofreu alteração $\left(189^{\circ} \mathrm{C}\right)$ (Tabela 1). Já no terceiro estágio de decomposição térmica não houve variação em $\mathrm{T}_{\text {onset3 }}$ e $\mathrm{T}_{\max 3}$ tanto antes quanto após o tratamento térmico; esse fato pode ser observado tanto no gráfico da Figura 7 quanto na Tabela 1. Como comentado anteriormente, estas são as temperaturas de decomposição dos nitratos e nitritos, demonstrando que o tratamento térmico não afetou estas estruturas.

O quarto estágio é atribuído à degradação da BNC. Observou-se que não houve alteração na temperatura de início da decomposição térmica $\left(\mathrm{T}_{\text {onse4}}\right)$ para a amostra após o tratamento térmico em relação à pura (Tabela 1). No entanto, não foi observado o quinto evento térmico em torno de 430 a $470^{\circ} \mathrm{C}$ referente à degradação dos resíduos carbonáceos da BNC pura.

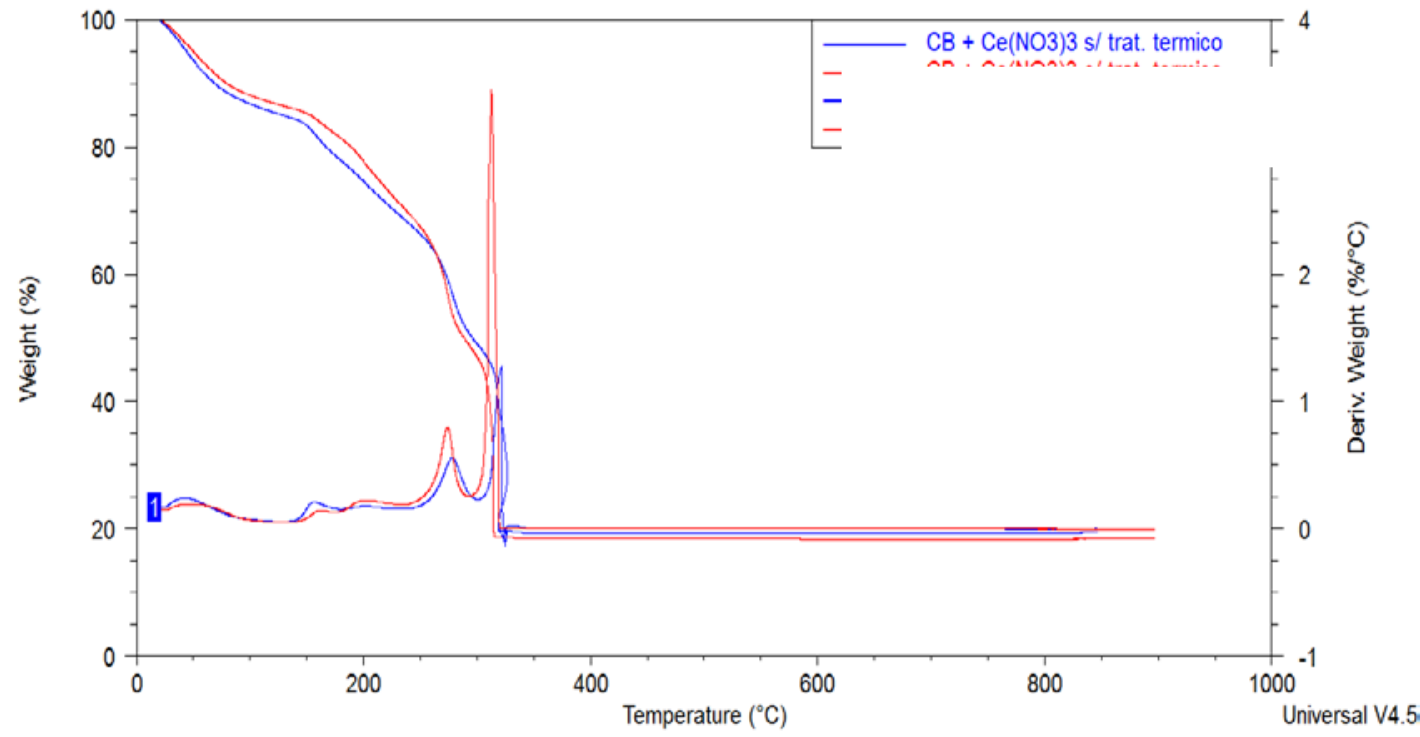

Figura 8: Curvas termogravimétricas (TG e DTG) das amostras de BNC incorporada com $\mathrm{Ce}\left(\mathrm{NO}_{3}\right)_{3}$, sem tratamento térmico (azul) e com tratamento térmico (vermelho).

\subsubsection{Análise do comportamento térmico da BNC incorporada com NPAg com e sem tratamento térmi- co}

A Figura 9 apresenta as curvas de TG e DTG para as amostras de BNC incorporadas com NPAg com e sem tratamento térmico. Observou-se que a adição das NPAgs na BNC implicaram em uma redução na estabilidade térmica em relação à BNC pura. De acordo com os dados extraídos do gráfico da Figura 8 e representados na Tabela 1 a $\mathrm{T}_{\text {onset } 4}$ foi registrada em $288^{\circ} \mathrm{C}$ para a amostra sem tratamento e $284^{\circ} \mathrm{C}$ após o tratamento térmico, enquanto para a BNC pura foi de $308^{\circ} \mathrm{C}$.

Para estas amostras foi possível observar o quinto evento térmico, referente à degradação dos resíduos carbonáceos da $\mathrm{BNC}$, que ocorreu entre $388^{\circ} \mathrm{C}$ e $390^{\circ} \mathrm{C}$ para a amostra que sofreu o tratamento térmico; a amostra sem tratamento térmico apresentou o pico, porém de forma muito sutil. 


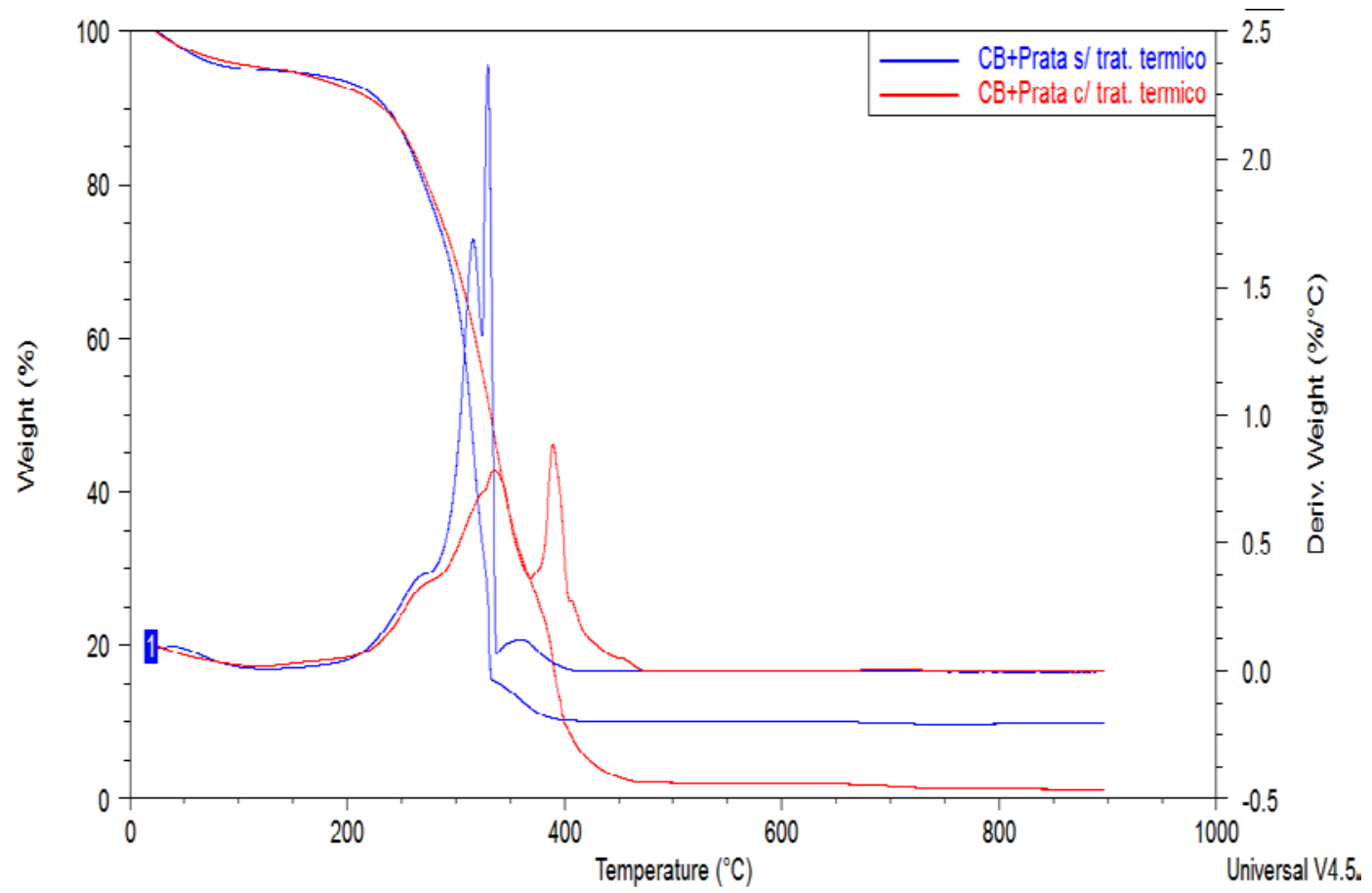

Figura 9: Curvas termogravimétricas (TG e DTG) das amostras de BNC incorporada com NPAg, sem tratamento térmico (azul) e com tratamento térmico (vermelho).

3.4.3 Análise do comportamento térmico da BNC incorporada com NPAg + $\mathrm{Ce}\left(\mathrm{NO}_{3}\right)_{3}$ com e sem tratamento térmico

Quando os dois compostos foram adicionados simultaneamente à membrana de BNC, observou-se uma atenuação nos estágios de decomposição térmica, referentes aos nitratos e nitritos do $\mathrm{Ce}\left(\mathrm{NO}_{3}\right)_{3}$, como pode ser observado na Figura 10.

Com relação à decomposição da BNC, não houve variação expressiva de $\mathrm{T}_{\text {onset4 }}$ sendo determinados os valores de $306^{\circ} \mathrm{C}$ e $309^{\circ} \mathrm{C}$, com e sem tratamento térmico. No entanto, $\mathrm{T}_{\text {onses }}$ e $\mathrm{T}_{\max 5}$ tiveram um incremento de $490^{\circ} \mathrm{C}$ e $531^{\circ} \mathrm{C}$, respectivamente, para a amostra sem tratamento térmico e $462^{\circ} \mathrm{C}$ e $527^{\circ} \mathrm{C}$ após o tratamento térmico (Tabela 1). 


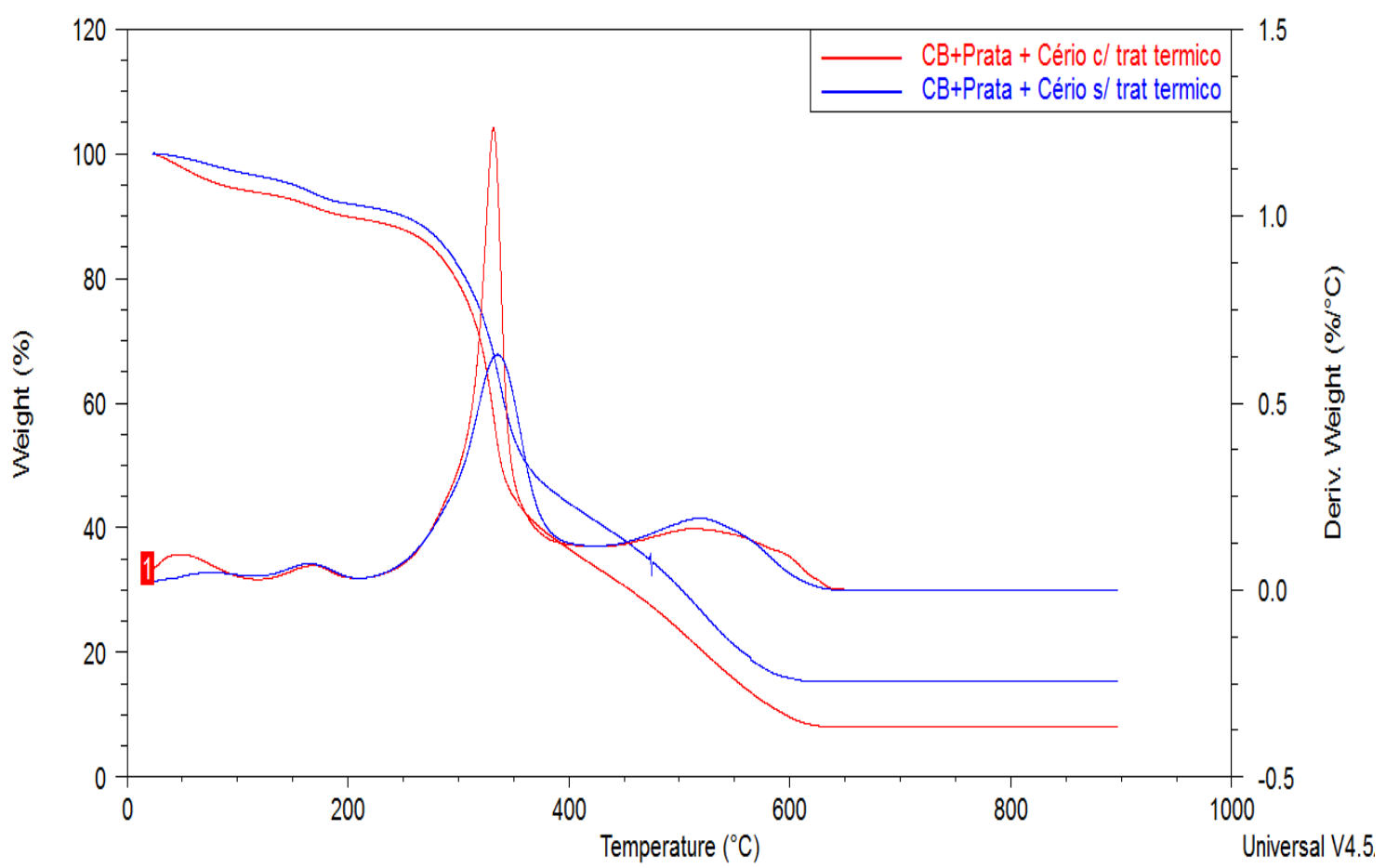

Figura 10: Curvas termogravimétricas (TG e DTG) das amostras de BNC incorporada com $\mathrm{NPAg}+\mathrm{Ce}\left(\mathrm{NO}_{3}\right)_{3}$, sem tratamento térmico (azul) e com tratamento térmico (vermelho).

Para as amostras que receberam o $\mathrm{Ce}\left(\mathrm{NO}_{3}\right)_{3}$ e NPAg simultaneamente, o comportamento térmico chamou a atenção em alguns aspectos; inicialmente, o perfil de degradação foi muito semelhante ao da BNC pura; no entanto, o percentual de perda de massa foi de $42 \%$ para a amostra sem tratamento térmico e $43 \%$ para a amostra tratada, o que representa uma diferença de cerca de $26 \%$ em relação à BNC pura. Já no terceiro evento térmico houve um incremento em $\mathrm{T}_{\text {onset } 5}$ de $490^{\circ} \mathrm{C}$ para a amostra sem tratamento térmico e $462^{\circ} \mathrm{C}$ para a amostra com tratamento térmico em relação à BNC pura. Variações semelhantes também foram observadas para $\mathrm{T}_{\max 5}$. Com relação às massas residuais, foi possível observar que, enquanto a BNC pura sofreu completa degradação térmica, as amostras adicionadas de $\mathrm{Ce}\left(\mathrm{NO}_{3}\right)_{3}$ e $\mathrm{NPAg}$ tiveram uma massa residual de 15,35\% antes e 8,24\% após o tratamento térmico, o que pode ser atribuído à adição dos elementos metálicos à membrana de celulose, o que elevou sua estabilidade térmica.

Bezzerra (2015) [25] também estudou a adição de nanopartículas de prata a amostras de ABS pela técnica de TGA, e também verificou que a presença de prata na matriz polimérica produziu um aumento na estabilidade térmica do material.

A partir das análises termogravimétricas foi possível observar que a estabilidade dos compostos adicionados à BNC apresentou pouca ou nenhuma alteração negativa quando adicionados simultaneamente e submetidos ao tratamento térmico. Desta forma, selecionou-se este método para a incorporação dos elementos metálicos à BNC que foi então submetida a outras técnicas de caracterização e identificada como BNC incorporada. 
Tabela 1: Dados de temperatura de início de degradação $\left(\mathrm{T}_{\text {onset }}\right)$, temperatura máxima de degradação $\left(\mathrm{T}_{\max }\right)$ e porcentagem de perda de massa, determinados a partir das curvas de TG e DTG das amostras de $\mathrm{Ce}\left(\mathrm{NO}_{3}\right)_{3}$, BNC pura e BNC incorporada, com e sem tratamento térmico.

\begin{tabular}{|c|c|c|c|c|c|c|c|}
\hline AMOSTRA & $\begin{array}{c}\text { PERDA } \\
\text { DE } \\
\text { MASSA } \\
1(\%)\end{array}$ & $\begin{array}{c}\text { ToNSET2 } \\
\left({ }^{\circ} \mathrm{C}\right)\end{array}$ & $\begin{array}{c}\text { PERDA } \\
\text { DE } \\
\text { MASSA } \\
2(\%)\end{array}$ & $\begin{array}{l}\mathrm{T}_{\mathrm{MAX} 2} \\
\left({ }^{\circ} \mathrm{C}\right)\end{array}$ & $\begin{array}{c}\text { ToNSET3 } \\
\left({ }^{\circ} \mathrm{C}\right)\end{array}$ & $\begin{array}{c}\text { PERDA } \\
\text { DE } \\
\text { MASSA } \\
3(\%)\end{array}$ & $\begin{array}{l}T_{\text {MAX3 }} \\
\left({ }^{\circ} \mathrm{C}\right)\end{array}$ \\
\hline $\mathrm{Ce}\left(\mathrm{NO}_{3}\right)_{3}$ & 6 & 199 & 18 & 208 & 252 & 30 & 266 \\
\hline BNC pura & 4 & --- & --- & --- & --- & --- & --- \\
\hline $\begin{array}{c}\mathrm{BNC}+\mathrm{Ce}\left(\mathrm{NO}_{3}\right)_{3} \\
\text { s/ trat. term. }\end{array}$ & 12 & 148 & 17 & 156 & 266 & 19 & 278 \\
\hline $\begin{array}{l}\mathrm{BNC}+\mathrm{Ce}\left(\mathrm{NO}_{3}\right)_{3} \\
\mathrm{cl} \text { trat. term. }\end{array}$ & 11 & 189 & 16 & 199 & 266 & 20 & 274 \\
\hline $\begin{array}{c}\text { BNC + NPAg sl } \\
\text { trat. term. }\end{array}$ & 4 & --- & --- & --- & --- & --- & --- \\
\hline $\begin{array}{l}\text { BNC + NPAg cl } \\
\text { trat. term. }\end{array}$ & 4 & --- & --- & --- & --- & --- & --- \\
\hline $\begin{array}{c}\mathrm{BNC}+\mathrm{Ce}\left(\mathrm{NO}_{3}\right)_{3}+ \\
\text { NPAg sl trat. } \\
\text { term. }\end{array}$ & 3 & --- & --- & --- & --- & --- & --- \\
\hline $\begin{array}{c}\mathrm{BNC}+\mathrm{Ce}\left(\mathrm{NO}_{3}\right)_{3}+ \\
\text { NPAgcl trat. } \\
\text { term. }\end{array}$ & 5 & --- & --- & --- & --- & --- & --- \\
\hline AMOSTRA & $\begin{array}{c}\text { ToNSET4 } \\
\left({ }^{\circ} \mathrm{C}\right)\end{array}$ & $\begin{array}{c}\text { PERDA } \\
\text { DE } \\
\text { MASSA } \\
4(\%)\end{array}$ & $\begin{array}{c}T_{\text {MAX4 }} \\
\left({ }^{\circ} \mathrm{C}\right)\end{array}$ & $\begin{array}{c}\text { ToNSET5 } \\
\left({ }^{\circ} \mathrm{C}\right)\end{array}$ & $\begin{array}{c}\text { PERDA } \\
\text { DE } \\
\text { MASSA } \\
5(\%)\end{array}$ & $\begin{array}{l}T_{\text {MAX5 }} \\
\left({ }^{\circ} \mathrm{C}\right)\end{array}$ & $\begin{array}{l}\text { RESÍDUO } \\
\text { (\%) }\end{array}$ \\
\hline $\mathrm{Ce}\left(\mathrm{NO}_{3}\right)_{3}$ & --- & -- & --- & --- & --- & --- & 3 \\
\hline BNC pura & 308 & 68 & 340 & 432 & 24 & 469 & 3 \\
\hline $\begin{array}{c}\mathrm{BNC}+\mathrm{Ce}\left(\mathrm{NO}_{3}\right)_{3} \\
\text { s/ trat. term. }\end{array}$ & 315 & 29 & 321 & --- & --- & --- & 20 \\
\hline $\begin{array}{c}\mathrm{BNC}+\mathrm{Ce}\left(\mathrm{NO}_{3}\right)_{3} \\
\text { cl trat. term. }\end{array}$ & 309 & 30 & 313 & --- & --- & --- & 19 \\
\hline $\begin{array}{l}\text { BNC + NPAg sl } \\
\text { trat. term. }\end{array}$ & 288 & 64 & 315 & 330 & 14 & 331 & 10 \\
\hline $\begin{array}{l}\text { BNC + NPAg cl } \\
\text { trat. term. }\end{array}$ & 284 & 64 & 335 & 388 & 25 & 390 & 2 \\
\hline $\begin{array}{c}\mathrm{BNC}+\mathrm{Ce}\left(\mathrm{NO}_{3}\right)_{3}+ \\
\text { NPAg sl trat. } \\
\text { term. }\end{array}$ & 306 & 42 & 336 & 490 & 34 & 531 & 15 \\
\hline $\begin{array}{c}\mathrm{BNC}+\mathrm{Ce}\left(\mathrm{NO}_{3}\right)_{3}+ \\
\text { NPAgcl trat. } \\
\text { term. }\end{array}$ & 309 & 43 & 332 & 462 & 39 & 527 & 8 \\
\hline
\end{tabular}

* A cor azul representa amostras sem tratamento térmico e, em vermelho amostras com tratamento térmico. As cores estabelecidas para a tabela seguem o mesmo padrão apresentado nos gráficos. 


\subsection{Microscopia eletrônica de varredura}

As imagens obtidas por Microscopia Eletrônica de Varredura (MEV) são apresentadas na Figura 11 (a, b, c e d). Em 11 a) pode ser observada a superfície superior BNC pura com aumento de 5.000×; a micrografia demonstra as fibrilas de celulose formando um arranjo randômico. Godinho et al. (2014) [4] também observaram em suas micrografias de BNC uma rede muito densa com poros de tamanhos variados que se prolongam para o lado inferior poroso da BNC; já em 11 b) pode ser observada a superfície inferior da BNC pura, com igual aumento. Esta micrografia apresenta uma maior compactação nas microfibrilas da BNC diminuindo a percepção de profundidade e espaços vazios. Este fato pode estar relacionado com o contato com o frasco de liofilização durante o processo de secagem. Oliveira et al. (2013) [26] também observaram em seus estudos com a produção de estruturas tubulares de BNC que a porção interna dos tubos sintetizados em contato direto com tubo de silicone também se apresentaram mais adensados.

Na presença de NPAg e $\mathrm{Ce}\left(\mathrm{NO}_{3}\right)_{3}$, ainda com aumente de 5.000×, a superfície inferior da BNC apresenta-se altamente fechada (Figura $11 \mathrm{c}$ ), sugerindo um revestimento das fibras da BNC pelos metais incorporados. Também é possível verificar a presença de alguns pontos brilhantes maiores; já com um aumento de $50.000 \times$, em 11 d), observa-se a superfície superior da BNC incorporada. Nesta, novamente é possível observar alguns pontos brilhantes com tamanho calculado em 71,3 nm, sugerindo a incorporação dos compostos.

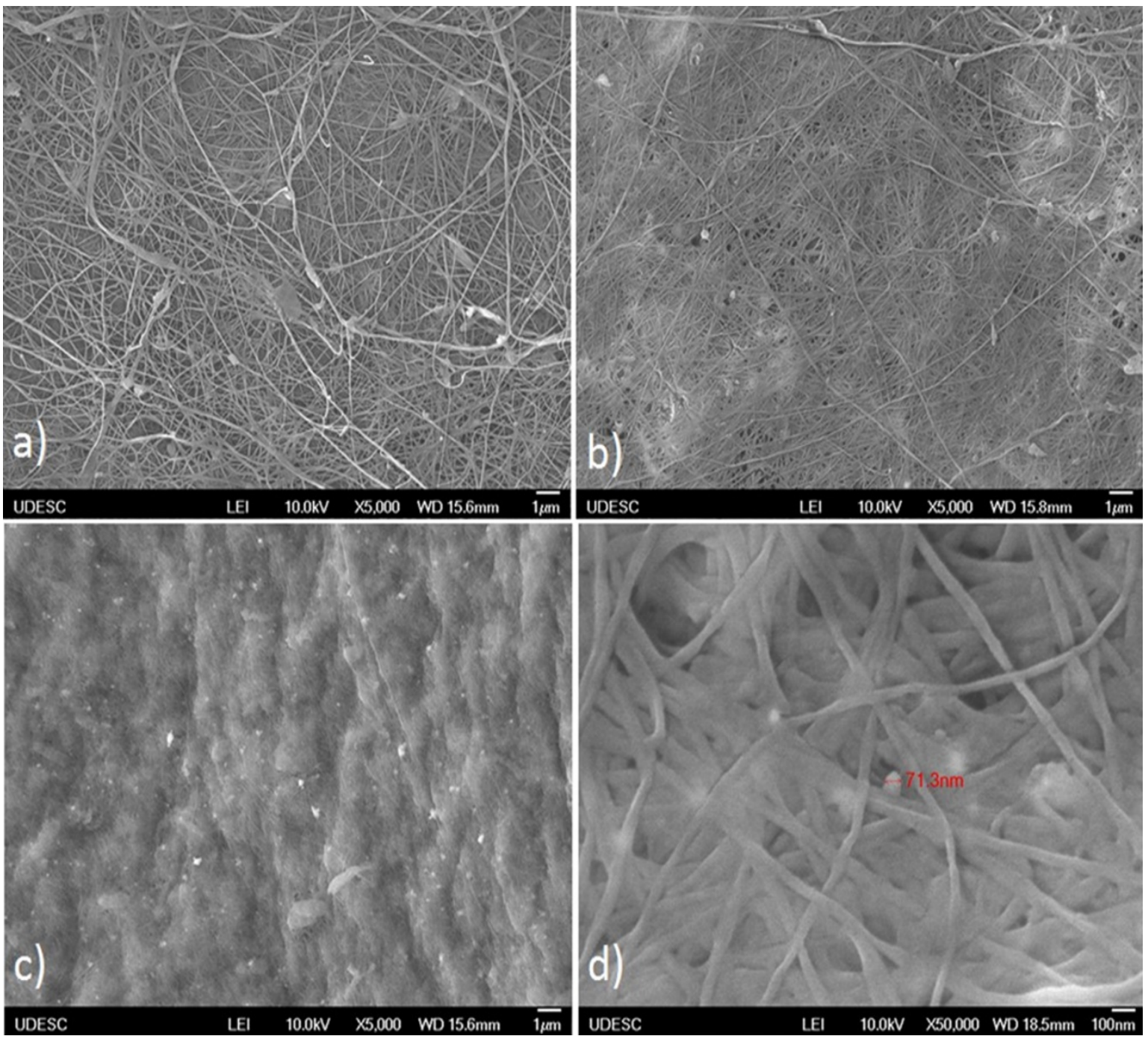

Figura 11: Imagens de MEV: a) superfície superior e b) superfície inferior da membrana de BNC pura com aumento de 5000x; c) superfície inferior da BNC incorporada com aumento de 5000× e d) superfície superior da BNC incorporada com aumento de $50000 \times$. 


\subsection{Determinação do conteúdo de água}

A Tabela 2 apresenta os resultados obtidos para a determinação do conteúdo de líquido na BNC pura e BNC incorporada.

As membranas de BNC apresentaram grande capacidade de retenção de água, em média 99\% conforme resultado apresentado na Tabela 2, referente à média e desvio padrão do ensaio realizado em triplicata. Os resultados apresentados estão de acordo com o obtido por Recouvreux (2008) [17].

Tabela 2: Conteúdo de água da BNC pura e BNC incorporada

\begin{tabular}{|c|c|c|c|c|c|c|c|}
\hline $\begin{array}{c}\text { AMOS- } \\
\text { TRA }\end{array}$ & $\begin{array}{c}\text { MASSA } \\
\text { BNC PURA } \\
\text { HIDRATA- } \\
\text { DA (G) }\end{array}$ & $\begin{array}{c}\text { MASSA } \\
\text { BNC PURA } \\
\text { LIOFILIZA- } \\
\text { DA (G) }\end{array}$ & $\begin{array}{c}\text { CONTEÚ- } \\
\text { DO DE } \\
\text { ÁGUA (\%) }\end{array}$ & $\begin{array}{c}\text { AMOS- } \\
\text { TRA }\end{array}$ & $\begin{array}{c}\text { MASSA } \\
\text { BNC INCOR- } \\
\text { PORADA } \\
\text { HIDRATADA } \\
\text { (G) }\end{array}$ & $\begin{array}{c}\text { MASSA } \\
\text { BNC INCOR- } \\
\text { PORADA } \\
\text { LIOFILIZADA } \\
\text { (G) }\end{array}$ & $\begin{array}{c}\text { CONTEÚ- } \\
\text { DO DE } \\
\text { ÁGUA (\%) }\end{array}$ \\
\hline CP 1 & 8,0581 & 0,0787 & 99,02 & CI 1 & 6,5156 & 0,1687 & 97,41 \\
\hline CP 2 & 8,8950 & 0,0957 & 98,92 & CI 2 & 6,8151 & 0,1868 & 97,26 \\
\hline CP 3 & 8,2303 & 0,0857 & 98,96 & CI 3 & 6,4925 & 0,1630 & 97,49 \\
\hline MÉDIA & 8,3945 & 0,0867 & 98,96 & & 6,6089 & 0,1728 & 97,39 \\
\hline $\begin{array}{l}\text { DESVIO } \\
\text { PA- } \\
\text { DRÃO }\end{array}$ & 0,4419 & 0,0085 & 0,0503 & & 0,1800 & 0,0124 & 0,1168 \\
\hline
\end{tabular}

De acordo com Barud (2006) [27], a película de BNC é extremamente hidrofílica, possuindo capacidade de absorção entre 60 a 700 vezes água em relação à sua massa.

As membranas de BNC incorporadas apresentam um pequeno decréscimo na capacidade de retenção de água, em média de 97,39\%.

\subsection{Capacidade de reidratação}

Observou-se que a capacidade de reabsorção de água da BNC pura após a liofilização foi de 97,08\% conforme apresentado no gráfico da Figura 12. A BNC incorporada apresentou uma menor capacidade de reabsorão inicial, 76,9\% em duas horas; no entanto, ao longo das 96 h de ensaio, chegou a 89,97\%.

BNC incorporada obteve menor capacidade de intumescimento porque a presença do $\mathrm{Ce}\left(\mathrm{NO}_{3}\right)_{3}$ e da NPAg afeta a capacidade de intumescimento. Qualquer fator que reduz o tamanho dos espaços vazios entre as cadeias ou poros terá efeito direto no mecanismo de transporte no hidrogel [28].

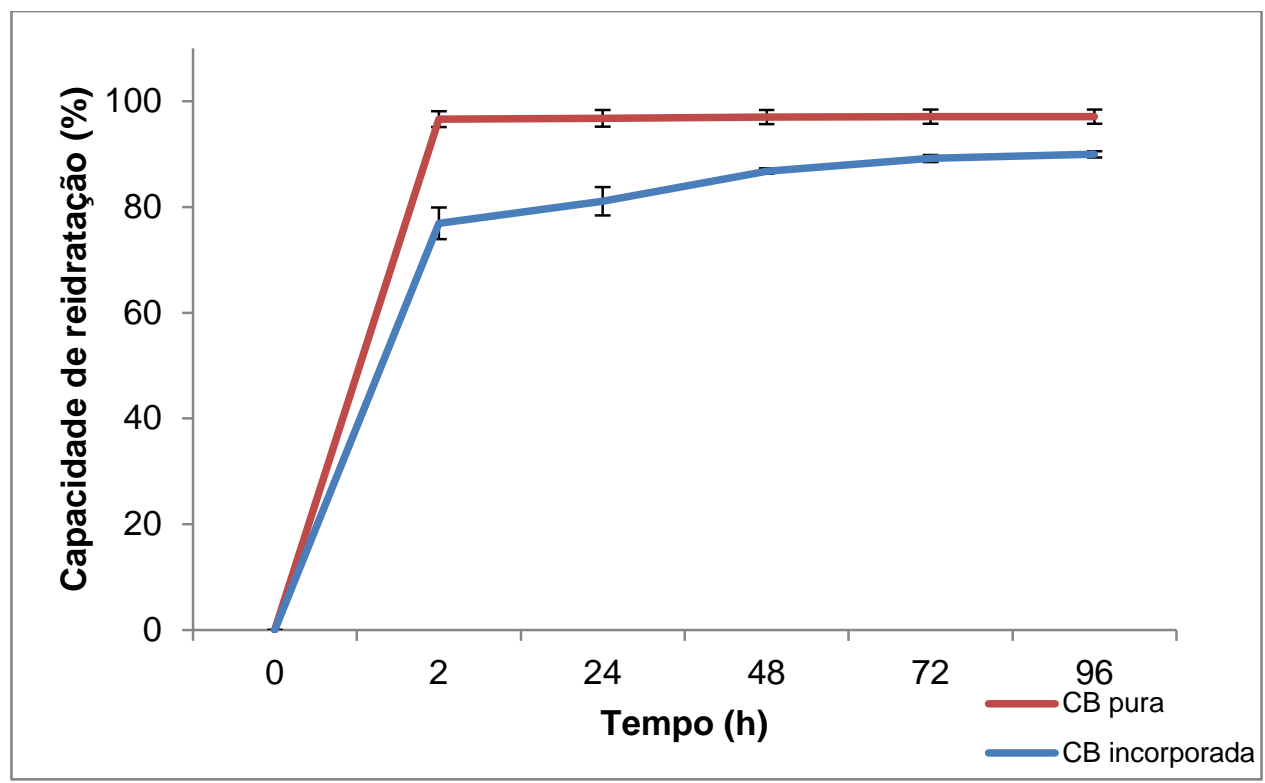

Figura 12: Capacidade de absorção de água da BNC pura e BNC incorporada. 


\subsection{Atividade microbiana}

A atividade antimicrobiana das NPAgs e $\mathrm{Ce}\left(\mathrm{NO}_{3}\right)_{3}$ incorporados na BNC foi avaliada sobre os microorganismos Gram-positivo S. aureus e P. aeruginosa, de acordo com a norma ASTM 2180-7, de 2012 [18].

O primeiro ensaio utilizou o meio ágar tripsina de soja sugerido pela norma; no entanto, mesmo após 48 h, o resultado obtido foi de $100 \%$ de redução microbiana, como pode ser observado na Figura 13 (a, b, c, d). Por este motivo, o teste de atividade antimicrobiana foi novamente realizado utilizando o meio de cultivo BHI para que uma possível limitação de nutrientes pudesse ser descartada como influência negativa sobre o crescimento microbiano. Os resultados podem ser observados na Tabela 3.

Observou-se que o percentual de redução microbiana foi mais efetivo para a $S$. aureus (98\%) do que para $P$. aeruginosa (89\%).

Muitos autores como Ruparelia et al. (2008), Carreira et al. (2009) e Antunes et al. (2013), apud Onofre (2014) [20], também observaram uma melhor ação de NPAg frente a bactérias Gram positivas, e associaram este fato à complexidade da parede celular de Gram negativas, que podem promover uma barreira contra as nanopartículas.
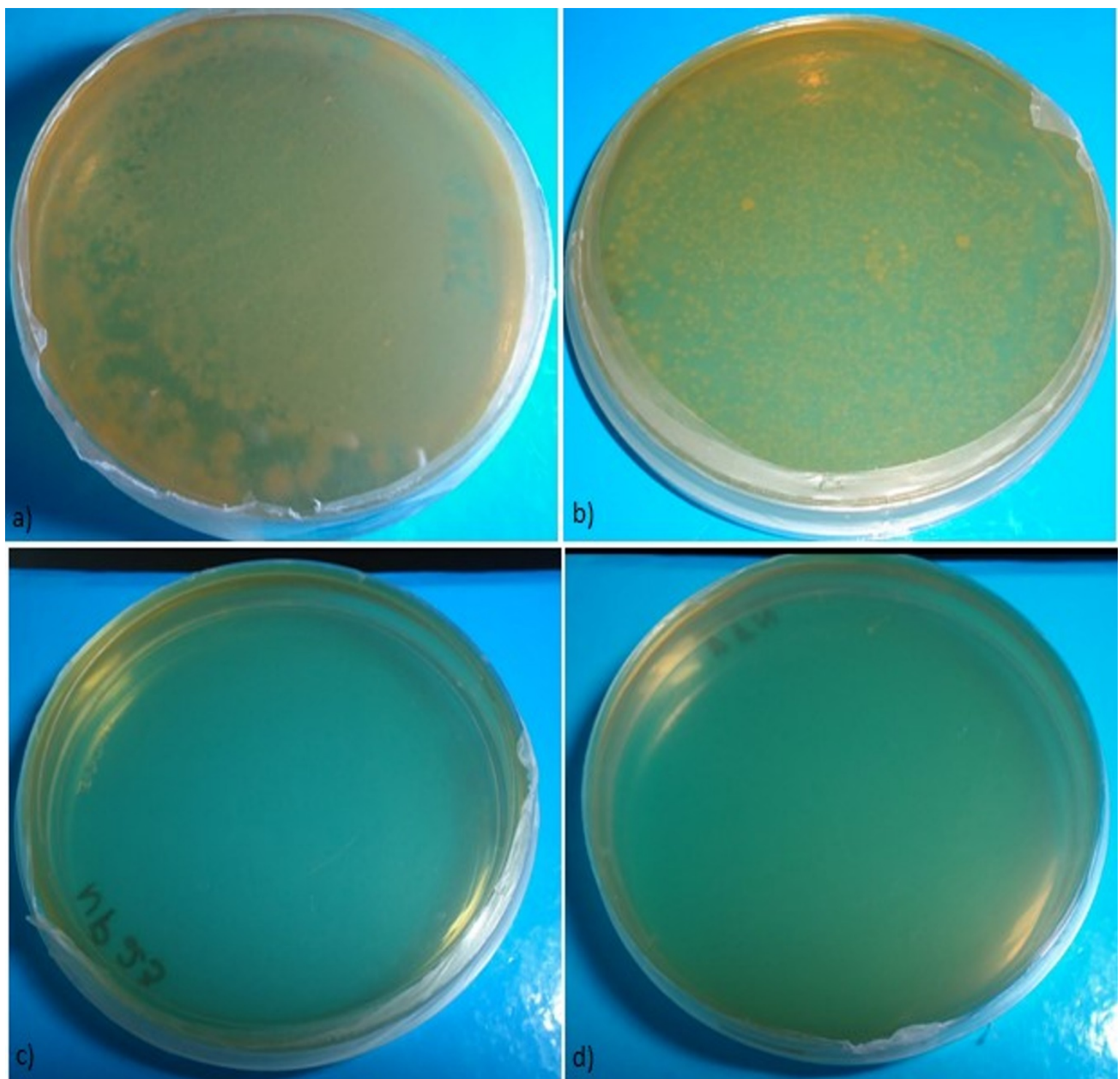

Figura 13: Fotografias tiradas das placas de Petri referentes ao ensaio antimicrobiano: BNC pura com a) P. aeruginosa e b) S. aureus; e BNC incorporada com: c) P. aeruginosa e d) S. aureus. 
Tabela 3: Dados obtidos do ensaio antimicrobiano com as amostras de BNC pura e BNC incorporada.

\begin{tabular}{|l|c|c|}
\hline AMOSTRA & $\begin{array}{c}\text { No DE COLÔNIAS DE de } \\
\text { S. aureus EM 24 HORAS }\end{array}$ & $\begin{array}{c}\text { No DE COLÔNIAS DE } \boldsymbol{P} \text {. } \\
\text { aeruginosa em 24 HORAS }\end{array}$ \\
\hline BNC pura & $3,1 \times 10^{5}$ & $1,8 \times 10^{3}$ \\
\hline BNC incorporada & 160 & 23 \\
\hline (\%) Redução bacteriana & 98 & 89 \\
\hline
\end{tabular}

Barud et al. (2008) [8] relatam que o mecanismo de inibição do crescimento microbiano observado para a prata não é inteiramente compreendido. Possíveis teorias apontam a interação de íons de prata com macromoléculas biológicas através de grupos de proteínas tiol $(-\mathrm{SH})$. Es tes íons de prata monovalentes $\left(\mathrm{Ag}^{+}\right)$substituiriam os íons $\mathrm{H}^{+}$dos grupos sulfidrilo ou tiol, inativando a proteína, diminuindo a permeabilidade da membrana e eventualmente causando a morte celular.

Onofre (2014) [20] lembra ainda que a prata é conhecida por apresentar baixa toxicidade em células animais, uma vez que estas não possuem grupos tióis exteriores; esses íons seriam inertes aos animais. Além disso, as concentrações necessárias para a eficácia contra os micro-organismos são tão baixas que não parecem ser capazes de trazer efeitos nocivos às células humanas.

\section{CONCLUSÕES}

Foram sintetizadas membranas de nanocelulose bacteriana e incorporadas com $\mathrm{Ce}\left(\mathrm{NO}_{3}\right)_{3}$ e NPAgs separadamente e conjuntamente sendo após submetidas a um tratamento térmico para a funcionalização das membranas.

A membrana formada pela incorporação com o $\mathrm{Ce}\left(\mathrm{NO}_{3}\right)_{3}$ e NPAgs simultaneamente e submetida ao tratamento térmico conservou as propriedades térmicas de ambos os materiais, e também boa capacidade de reidratação e um potencial de redução microbiana de 98\% para Staphylococcus aureus. A análise de microscopia eletrônica de varredura apresentou alteração na morfologia, redução de tamanho dos poros e presença de partículas sugerindo a incorporação dos compostos.

Fazem-se necessários ainda estudos de citotoxicidade e avaliação do potencial imunomodulador; no entanto, estes estudos indicam a possibilidade de obtenção de um curativo de pele com ação antimicrobiana, próprio para o tratamento de queimaduras, como um artefacto de engenharia tecidual.

\section{AGRADECIMENTOS}

Os autores agradecem ao Governo do Estado de Santa Catarina pela bolsa de Iniciação Científica Art. 170, e à Profa. Dra. Derce de Oliveira Souza Recouvreux (UFSC - Campus de Joinville) pela disponibilização das cepas de G. hansenii.

\section{BIBLIOGRAFIA}

[1] BHATIA, A., O’BRIEN, K., CHEN, M., et al., "Dual therapeutic functions of F-5 fragment in burn wounds: preventing wound progression and promoting wound healing in pigs", Molecular Therapy - Methods \& Clinical Development, pp. 1 - 11, Jun. 2016.

[2] DAI, T., HUANG, Y., SHARMA, S.K., et al., “Topical Antimicrobials for Burn Wound Infections” Recent Pat Antiinfect Drug Discov, v. 5, n. 2, pp. 124-151, Jun. 2010.

[3] VIEIRA, J. C., BADIN, A. Z. D., CALOMENO, L. H., et al., "Membrana porosa de celulose no tratamento de queimaduras”, Arquivos Catarinenses de Medicina, v.36, n. 1, pp. 90-94, 2007.

[4] GODINHO, J. F., BERTI, F. V., MÜLLER, D., et al., "Incorporation of Aloe vera extracts into nanocellulose during biosynthesis” Celulose, v. 23, n. 1, pp. 545 - 555, Fev. 2016.

[5] ZHIJIANG, C., YANG, G. "Bacterial cellulose/collagen composite: Characterization and first evaluation of cytocompatibility”, Journal of Applied Polymer Science, v.120, n. 5, pp. 2938-2944, Jan. 2011.

[6] LOPES, R. "Funcionalização de celulose bacteriana com peptídeo RGD para reparação tecidual de pele”, Dissertação de M. Sc., Universidade Federal Paulista, Araraquara, SP, Brasil, 2015. 
[7] REVISTA PESQUISA FAPESP, http://revistapesquisa.fapesp.br/2004/07/01/celulose-na-pele/. Acessado em outubro de 2016

[8] BARUD, H.S., REGIANE, T., BARRIOS, C., et al., "Self-supported silver nanoparticles containing bacterial cellulose membranes” Materials Science and Engineering: C, v.28 n. 4, pp. 515-518, Mai. 2008.

[9] CHAKRABORTI, S., MANDAL, A.K., SARWAR, S., et al., "Bactericidal effect of polyethyleneimine capped $\mathrm{ZnO}$ nanoparticles on multiple antibiotic resistant bacteria harboring genes ofhigh-pathogenicity island”, Colloids and Surfaces B: Biointerfaces, v.121, pp.44-53, 2014.

[10] CHELLAN, P., SADLER, P.J. “The elements of life and medicines”, Phil.Trans. R.Soc.A, v. 373, n. 2037, Mar. 2015.

[11] HESTRIN, S., SCHARAM, M. "Synthesis of cellulose by Acetobacter xylinum. 2. Preparation of freeze-dried cells capable of polymerizing glucose to celulose”, Biochemical Journal, v.58, n. 2, pp. 345352, Out. 1957.

[12] ANTÔNIO, R. V., RECOUVREUX, D. O. S., NAZARIO, A. C., et al., "Produção de celulose bacteriana a partir de diferentes substratos”, Revista Técnico Científica da IFSC, v.3, n. 1, pp. 176-182, Out. 2012.

[13] SILVEIRA. J.F.C. Obtenção e Incorporação de Nanocristais de em Matriz Polimérica de Poli (L-Ácido Láctico), Dissertação de M. Sc., UNIVILLE, Joinville, SC, Brasil, 2016.

[14] NOGUEIRA, A. L., MACHADO, R. A. F., SOUZA, A. Z., et al., "Synthesis and Characterization of Silver Nanoparticles Produced with a Bifunctional Stabilizing Agent”, Industrial \& Engineering Chemestry Research, v. 53, n. 9, pp. 3426-3434, Fev. 2014.

[15] NOGUEIRA, A. L., MACHADO, R. A. F., SOUZA, A. Z., et al., "Influence of Process Parameters and Scalability of the Semi-Batch Production of Functionalized Silver Nanoparticles", The Canadian Journal of Chemical Engineering, v. 94, pp. 1472-1485, Ago. 2016.

[16] FRATTINI, A., PELLEGRI, N., NICASTRO, D., et al., "Effect of amine groups in the synthesis of Ag nanoparticles using aminosilanes”, Materials Chemistry and Physics, v. 94, n. 1, pp. 148, Nov. 2005.

[17] RECOUVREUX, D. O. S. "Desenvolvimento de Novos Biomateriais Baseados em CB para Aplicações Biomédicas e de Engenharia de Tecidos”, Tese de D. Sc., UFSC, Florianópolis, SC, Brasil, 2008.

[18] ASTM - American Society for Testing and Materials. E2180-7: Standard Test Method for Determining the Activity of Incorporated Antimicrobial Agent (s) In Polymeric or Hydrophobic Materials, 2012.

[19] WU, K.H., CHANG, Y.C., TSAI, W.Y., et al., "Effect of amine groups on the synthesis and antibacterial performance of Ag nanoparticles dispersed in aminosilanes-modified silicate", Polymer Degradation and Stability, v. 95, n. 12, pp. 2328-2333, Dec. 2010.

[20] ONOFRE, N.A., "Desenvolvimento e Caracterização de Filmes Poliméricos a partir de Ágar, Agarose e Kefirana com Incorporação de Nanopartículas de Prata”, Dissertação de M. Sc., UFPE, Recife, PE, Brasil, 2014.

[21] ALCÂNTARA, M. T. S., Hidrogéis poliméricos com NPAg para aplicações médicas. Tese de D.Sc., Instituto de Pesquisas Energéticas e Nucleares, Universidade de São Paulo, São Paulo, SP, Brasil, 2013.

[22] QUEIROZ, C. A. S., ÁVILA, D. M., ABRÃO, A., et al., "Síntese e caracterização de precursores de cério de alta pureza”, Cerâmica, v.47, n. 301, pp. 45-50, Jan. 2011

[23] LIMA, L.R., SANTOS, D.B., SANTOS, M.V., et al., "Nanocristais de Celulose a partir de celulose bacteriana”, Química Nova, v. 38, n. 9, pp. 1140-1147, Ago. 2015.

[24] TEIXEIRA, E. M., OLIVEIRA, C. R., MATTOSO, L. H. C., et al., "Nanofibras de algodão obtidas sob diferentes condições de hidrólise ácida”, Polímeros, v.20, n. 4, pp. 264-268, Nov. 2010.

[25] BEZERRA, A. V. A. "Síntese, Caracterização e Avaliação da Atividade Biocida de Nanopartículas de Prata em Filmes de Poliestireno”, TCC de Graduação, UFSC, Florianópolis, SC, Brasil, 2015.

[26] OLIVEIRA, V.A., RAMBO, C.R., PORTO, L.M. "Produção e degradação in vitro de estruturas tubulares de celulose bacteriana”, Polímeros, v. 23, n. 4, pp. 559-564, Ago. 2013.

[27] BARUD, H.S. "Preparo e caracterização de novos compósitos de celulose bacteriana", Dissertação de M.Sc., UNESP, Araraquara, São Paulo, Brasil, 2006.

[28] MOLINA, M.A., RIVAROLA, C.R., BARBERO, C.A. "Study on partition and release of molecules in superabsorbent thermosensitive nanocomposites”, Polymer, v.53, n. 2, pp. 445-453, Jan. 2012. 